\title{
Obstetrician's Role in the Protection, Promotion and Support of Infant and Young Child Feeding
}

\author{
SARIA TASNIM
}

\begin{abstract}
:
Obstetricians have the privilege to serve the women during pregnancy, childbirth and beyond. This review is made to highlight obstetrician's role in preparing women for breast feeding and complementary feeding as well as supporting them in case of any problem related with infant feeding.
\end{abstract}

Key words: Breast feeding, complementary feeding.

\section{Introduction:}

Obstetricians have the opportunity to be with the women during pregnancy, labour and puerperium. They have an important role in the success of optimum breastfeeding. Although breast feeding is a natural phenomenon, at times there are problems that interfere with the practice. Preparation for lactation begins long before the baby is born, that is manifested through physiological changes in breast during pregnancy. The glandular component of the breast increases under hormonal control and all factors for milk production are accumulated in the breast during pregnancy. As soon as the baby is born and put to breast the suckling stimuli start secretion of prolactin and oxytocin hormone. Prolactin will prepare milk in the breast and oxytocin will carry out milk let down ${ }^{1}$. Whenever, there is some disturbance in the normal physiology, lactation is hampered and some management is needed to overcome the problems. It is stated that successful nursing depends on the successful interaction of mother and infant, with appropriate support from the father, family and available health care $^{2}$.

Optimum infant and young child feeding means exclusive breast feeding for 6 months (180 days) and starting nutritionally adequate and safe complementary feeding from the age of 6 months with continued breast feeding upto 2 years of age or beyond ${ }^{3,4}$. Obstetricians have a pivotal role in all sphere of infant feeding like initiating and sustaining breast feeding, maintaining exclusive breast feeding and overcoming difficulties related to breast lesion and lactation.

\section{Role in Timely initiation of breast feeding/ Promotion:}

Timely initiation of breast feeding within one hour of birth would cut $22 \%$ of all neonatal deaths. The study estimates that of the four million babies who die in the developing world each year in the first month of life, almost one million of them could be saved through breast feeding ${ }^{5}$. In Bangladesh neonatal mortality is 32 per thousand live birth and half of those deaths are due to neonatal sepsis ${ }^{6}$. Evidence shows that new born babies who initiated breast feeding within one hour are less likely to die of neonatal sepsis and overall late initiation (after day 1 ) is associated with a 2.6 fold risk ${ }^{7}$.

Right after birth the sucking reflex is most active and babies are more alert during the first 30-60 minutes. So, if babies are put to mother's breast within this period chances of exclusive breast feeding increases. As obstetricians are delivering the baby it is their prime responsibility to ensure skin to skin touch immediately after birth, for early initiation of breast feeding to encourage rooming in, and bedding in and thus establishing exclusive breast feeding.

Management of breast-feeding is required in three stages: i) prenatal period, ii) immediate postpartum and iii) postnatal period. In each stage there are specific needs and problems that should be dealt with. For example, most important factor during prenatal period is to motivate the expectant mothers for breast feeding, building their confidence and intimating proper technique of breast feeding ${ }^{2}$. It has been shown that mothers with difficult labour had more problems with 
breast feeding. Infants born by Vacuum extraction or caesarean section had delayed sucking and receive more supplements. ${ }^{8}$ Parity increase chances of success in lactation 4 . Mode of delivery, duration of labour, labour medication, use of artificial feeding and pacifier negatively influence breast feeding and when these factors are present, extra care should be made to support the mother's efforts to breastfeed ${ }^{10}$.

To initiate breast feeding early women need accurate information, motivation and assistance at the time of delivery. Obstetrician can prepare pregnant women during antenatal visits by informing them the advantages and techniques of breast feeding. They can help the new mother to start breast feeding within half an hour of the birth ensuring that the baby is in the right sucking position. Obstetrician should be vigilant to avoid any practice that could hamper breast feeding like giving prelacteal feed or Pacifier or keeping the baby away from the mother. Evidence shows that simple interventions after delivery such as rooming in. skin to skin contact and support to mother are likely to have greatest impact on early initiation of breast feeding ${ }^{11}$.

\section{Role in establishing exclusive breast-feeding}

Although in our social context breast-feeding is a norm but this does not guarantee timely initiation of breast feeding and exclusive breast-feeding unless some practical help is provided. There is often delay in initiation of breast feeding or infrequent feeds. Anxiety due the low volume of colostrums and the physiological delay for milk let down may provoke the women to supplement breast feeding with artificial milk thus disrupting exclusive breast feeding. In case of maternal problems like pain following caesarean section or episiotomies breast feeding practice may be jeopardized. Improper position and attachment can lead to lactation problems like sore nipple and hamper exclusive breast feeding. Misconception about continuing breast feeding during childhood illness like diarrhea, pneumonia exist in the society. This temporary cessation of breastfeeding is a great threat to sustaining exclusive breast feeding.

Report from South Asian countries reveal that initiation of breast-feeding within one hour was $24 \%$ in Bangladesh, 26\% in Pakistan, 31\% in Nepal and 75\% in Srilanka ${ }^{12}$. The effect of these breastfeeding patterns is reflected in the neonatal mortality rates for these countries: $40-50$ per 1000 live births for
Bangladesh, India and Pakistan, while in Srilanka the rate is as low as 11 per 1000 live births ${ }^{12}$.

\section{Role in baby friendly hospital initiative (BFHI)}

Breast milk is recognized as the ideal food for babies and baby friendly hospital initiative was launched in 1991 based on the WHO/ UNICEF joint statement recommendations ${ }^{13}$. The obstetrician has important role in adopting all ten steps specified in $\mathrm{BFHI}^{14}$. The breast feeding policy can be implemented and communicated to all other staffs in the maternity by the obstetrician. They can play leading role in training the staffs of the maternity for promotion of breast feeding and giving practical help to the mother.. The obstetrician can provide technical support and monitoring to demonstrate proper techniques of breastfeeding and expression of breast milk.

Community awareness can be raised through mass media; women's club, fostering mother support group under the guidance of the obstetrician. Rooming in and bedding in practices are best advocated by the obstetrician. They should adhere to the international guidance outlined in the international code of marketing of breast milk substitutes and vigilant for the implementation of BMS in the hospital and also in the community ${ }^{15}$. Recently the code has been transformed into a law in Bangladesh in the name of Breast milk substitutes, baby food, commercially manufactured supplementary baby food and its equipment (regulation of marketing) Act, 2013. ${ }^{15}$ Obstetricians should avoid to attend any seminar symposium or conference sponsored by milk companies to avoid any conflicts of interest ${ }^{16}$. Obstetricians should comply with breast milk substitute law and put efforts to create awareness about the legislation among other health care providers and public. They should be vigilant to notice any violation of the law and act accordingly.

\section{Role in promoting complementary feeding}

The target age range for complementary feeding is generally 6-24 months, however breast feeding should continue for 2 years and beyond. Optimal complementary feeding depends not only on what is fed but also on how, when, where \& by whom the child is fed. Children are vulnerable to under nutrition during period of complementary feeding because either the food is not nutritionally adequate in quality or amount is insufficient or the baby is not fed in appropriate way. BDHS 2011 shows only 21\% of 
children aged 6-23 months are fed with all 3 principles of IYCF practices ${ }^{6}$. Guiding Principles for complementary feeding has been recommended that emphasize on responsive feeding applying principles of psychosocial care, to practice good hygienic \& proper food handling 4 .

Obstetrician can narrate about importance of timely initiation of complementary feeding at 6 months during antenatal and postnatal counseling. Types of food to be offered, recommended amount and frequency of feeds according to age of baby and feeding principle can be discussed during post natal visits also. Breast-feeding counseling should include complementary feeding as well. Government of Bangladesh has implemented a policy of maternity leave for 6 months for working women to support EBF for 6 months. When the mother visits her obstetrician for a fitness certificate before joining to work after maternity leave that provides an opportunity to discuss about the preparation for complementary feeding with her. Government has adopted national guideline for IYCF and obstetrician can take active role in advocacy and implementation of the strategy ${ }^{17}$. They can also conduct research on breast-feeding issues to make the practice evidence based.

Obstetrician as a leader of maternal health care team can play the prime role in training different level of health care providers on IYCF, strengthen lactation management centres to provide co-ordinated services for lactation as well as complementary feeding issues. Periodic assessement of breast-feeding practices in the work place can be done by the obstetrician during her routine visits. Obstetrician can also extend their expertise to deal with women with any lactation problem in different context beyond the working area e.g. responding to telephone calls or visit to the community. Breast-feeding is the right of the infant and mother as well and obstetrician are the gate keepers to protect this right.

\section{Conclusion:}

Optimum IYCF practice is vital for child growth and development. Mother is the key personnel for maintaining nutrition of the child from intrauterine life to birth and beyond. As mother and infant is a dyad, obstetricians have the responsibility to take care of both mother and infant through motivation and support to the mothers for successful infant \& young child feeding.

\section{References:}

1. WHO, Infant and young child feeding model chapter for textbooks for medical students \& allied health professionals: World Health Organization 2009. Geneva.

2. Lawrence, 2005 Lawrence |RA and Lawrence RM. Breastfeeding, A Guide for the Medical Profession, $6^{\text {th }}$ Ed. Elsevier Mosby, Phila, PA. 2005:

3. Kramer MS, Kakuma R. The optimal duration of exclusive breastfeeding: a systematic review. Geneva, World Health Organization, 2001 (WHO/ $\mathrm{NHD/01.08;WHO/FCH/01.23).}$

4. PAHO/WHO. Guiding principles for complementary feeding of the breastfed child. Washington DC, Pan American Health Organization/World Health Organization, 2002.

5. Edmond KM, Zandoh C, Quigley MA, AmengaEtego S, Owusu-Agyei S, Kirkwood BR. Delayed Breastfeeding lactation increases risk of neonatal Mortality Pediatrics, 2006 117:380-386.

6. Bangladesh Health and Demographic survey 2007. National institute of Population research and training. Preliminary analysis

7. Edmond KM, Kirkwood BR, Amenga-Etego S, Owusu-Agyei S, Hurt LS. Effect of early infant feeding practices on infection-specific neonatal mortality: an investigation of the causal links with observational data from rural Ghana. Am J Clin Nutr. 2007 86(4):1126-31.

8. Vibeke Vestermark, Claus K, Hogdall, Michael Birch, Grete plenov, Kim Toftager-Larsen. Influence of the mode of delivery on initiation of breast-feeding European, Journal of Obstetrics \& Gynaecology and Reproductive Biology. 1991; 38, (1), 4 :33-38.

9. Dewey K.G., Finley D. A., Strode MA., Lönnerdal B. Relationship of maternal Age to breast Milk Volume and Composition, Human lactation. M. Hamosh et al (eds) Plenum Press, New York. 1986. p 263-273.

10. Dewey KG, Nommsen-Rivers L.A. Heinie MJ and Cohen RJ. Risk factors for suboptimal infant breastfeeding behavior, delayed onset of lactation, and excess neonatal weight loss, Pediatrics. 2003; 112(3):607-619. 
11. Jana AK. Interventions for promoting the initiation of breastfeeding: RHL commentary (last revised: 2 March 2009). The WHO Reproductive Health Library, Geneva: World Health Organization.

12. The state of the world's breast-feeding: report card. Initiation of breastfeeding within 1 hour. New Delhi: International Baby Food Action Network Asia. Available at: http://www. world breastfeedingtrends.org/reportcard/RCIB.pdf.Accessed 1 Feb 2009.

13. UNICEF The Baby-Friendly Hospital Initiative: http://www.unicef.org/ programme/breastfeeding/ baby.htm
14. WHO. Ten steps to successful breast feeding. World Health Organization. 1989. Geneva

15. Breast milk substitutes, baby food, commercially manufactured supplementary baby food and its equip ments (regulation of marketing) Act, 22nd September 2013

16. M Q-K Talukdar, How Paediatricians can Promote, Protect and Support Breastfeeding, Bangladesh J Child Health 2011; 35(3):79-83

17. GOB. National strategy for infant and young child feeding in Bangladesh. IPHN and UNICEF: Bangladesh Gazette. Sunday $22^{\text {nd }}$ September 2013. 